\title{
Outcome of Critically Ill Patients with Testicular Cancer
}

\author{
Silvio A. Namendys-Silva, ${ }^{1,2,3}$ Mireya Barragán-Dessavre, ${ }^{1}$ Andoreni R. Bautista-Ocampo, ${ }^{1}$ \\ Francisco J. García-Guillén, ${ }^{1}$ Bertha M. Córdova-Sánchez, ${ }^{1}$ Edgar Constantino-Hérnandez, ${ }^{1}$ \\ Paulina Correa-García, ${ }^{1}$ Octavio González-Chon, ${ }^{3}$ and Angel Herrera-Gómez ${ }^{1}$
}

\author{
${ }^{1}$ Department of Critical Care Medicine, Instituto Nacional de Cancerología, 14080 Mexico City, Mexico \\ ${ }^{2}$ Department of Critical Care Medicine, Instituto Nacional de Ciencias Médicas y Nutrición Salvador Zubirán, \\ 14000 Mexico City, Mexico \\ ${ }^{3}$ Department of Critical Care Medicine, Fundación Clínica Médica Sur, 14050 Mexico City, Mexico \\ Correspondence should be addressed to Silvio A. Namendys-Silva; snamendys@incan.edu.mx
}

Received 5 May 2017; Accepted 19 September 2017; Published 26 October 2017

Academic Editor: Christian Schwentner

Copyright (c) 2017 Silvio A. Namendys-Silva et al. This is an open access article distributed under the Creative Commons Attribution License, which permits unrestricted use, distribution, and reproduction in any medium, provided the original work is properly cited.

\begin{abstract}
Purpose. To evaluate the clinical characteristics and outcomes of critically ill patients with testicular cancer (TC) admitted to an oncological intensive care unit (ICU). Methods. This was a prospective observational study. There were no interventions. Results. During the study period, 1,402 patients with TC were admitted to the Department of Oncology, and 60 patients (4.3\%) were admitted to the ICU. The most common histologic type was nonseminomatous germ cell tumors (55/91.7\%). The ICU, hospital, and 6-month mortality rates were $38.3 \%, 45 \%$, and $63.3 \%$, respectively. The Cox multivariate analysis identified the white blood cells count $(\mathrm{HR}=1.06,95 \% \mathrm{CI}=1.01-1.11$, and $P=0.005)$, ionized calcium (iCa) level $(\mathrm{HR}=1.23,95 \% \mathrm{CI}=1.01-1.50$, and $P=0.037)$, and 2 or more organ failures during the first 24 hours after ICU admission $(\mathrm{HR}=3.86,95 \% \mathrm{CI}=1.96-7.59$, and $P<0.001)$ as independent predictors of death for up to 6 months. Conclusion. The ICU, hospital, and 6-month mortality rates were $38.3 \%$, $45 \%$, and $63.3 \%$, respectively. The factors associated with an increased 6-month mortality rate were white blood cells count, iCa level, and 2 or more organ failures during the first 24 hours after ICU admission.
\end{abstract}

\section{Introduction}

Testicular cancer (TC) represents between $1 \%$ and $1.5 \%$ of male neoplasms. TC shows excellent cure rates. Germ cell tumors (GCTs) are classified as seminoma or nonseminoma. More than $90 \%$ of patients diagnosed with GCTs are cured, including $70 \%$ to $80 \%$ with advanced tumors who are treated with chemotherapy [1]. The main factors contributing to this outcome are careful staging at the time of diagnosis; adequate early treatment based on chemotherapeutic combinations, with or without radiotherapy and surgery; and very strict follow-up and salvage therapies [2]. Critically ill patients with TC may require intensive care due to different causes such as acute respiratory failure within a few days of initiation of the chemotherapy [3], postanesthetic recovery, infection, and sepsis; however no studies have reported the prognosis of this group of critically ill patients who require intensive care. Because of this limitation, we decided to perform the present study, aiming to evaluate the clinical characteristics and outcomes of critically ill patients with TC admitted to an oncological intensive care unit (ICU).

\section{Methods}

This was a prospective observational study of 60 consecutive critically ill cancer patients with TC admitted to the ICU of the Instituto Nacional de Cancerología (INCan), located in Mexico City, from February 2008 to February 2015. This study was approved by the Bioethics Committee of INCan, and the requirement for informed consent was waived (Rev/09/15).

Demographic, clinical, and laboratory data were collected during the first day of the ICU stay and included the primary histology, sites of metastasis, International Germ Cell Consensus Classification [4], performance status (Eastern 
Cooperative Oncology Group scale) [5] during the last month before hospitalization, tumor markers, need for mechanical ventilation (MV), need for vasopressor therapy, need for hemodialysis, length of invasive MV, length of stay in the hospital wards before ICU admission, and outcome data (ICU, hospital, and 6-month mortality rate). The length of the ICU stay was measured as the number of days from ICU admission until ICU discharge or death. The length of stay in the hospital before ICU admission was measured as the number of days from admission to the hospital until ICU admission. The Acute Physiology and Chronic Health Evaluation II score [6] and the Mexican Sequential Organ Failure Assessment (MEXSOFA) score [7] were calculated using the worst values for acute physiological variables during the first 24 hours after admission to the ICU. Organ failure was defined as a MEXSOFA score $>2$ for any of the five organs/systems evaluated. The patients were divided into two groups: survivors and nonsurvivor.

2.1. Data Presentation and Statistical Analyses. For the statistical analyses we followed the methods of NamendysSilva et al. [8]. Continuous variables are expressed as the means \pm standard deviation or as medians and interquartile ranges (IQRs), if the distribution was skewed. Categorical variables are expressed as the percentage. Student's $t$-test or the Mann-Whitney $U$-test were used to compare continuous variables according to the data distribution (normal or nonnormal, resp., determined using the Kolmogorov-Smirnov test), and the chi squared or Fisher's exact test was used to compare categorical variables.

Cox proportional hazards univariate and multivariate analysis were used to identify factors with potential prognostic significance for 6-month survival. Variables selected in the univariate analysis $(P<0.25)$ and those considered clinically relevant were included in a multivariable Cox proportional hazards regression model to estimate the independent contribution of each variable to the mortality. The results were reported using hazard ratios (HRs) and the corresponding 95\% confidence intervals (95\% CIs). Survival time was defined as the time (days) from ICU admission to death from any cause up to 6 months of follow-up. Patient survival was analysed using the Kaplan-Meier method and compared between groups by the log-rank test. A two-sided $P$ value < 0.05 was used to determine statistical significance. Statistical analyses were performed using the Statistical Package for the Social Sciences software (version 22.0; SPSS, Chicago, IL, USA).

\section{Results}

During the study period, 1,402 patients with TC were admitted to the Department of Oncology of the INCan, and 60 patients $(4.3 \%)$ were evaluated by intensivists at the request of ward oncologists responsible for the patient. The 60 patients with TC were admitted to the ICU of the INCan. The mean age of the patients was $28.3 \pm 8.2$ years. The most common histologic type was nonseminomatous germ cell tumors (55/91.7\%), and 5 (8.3\%) were seminomas. In total $98.3 \%$ of the patients underwent an orchiectomy.

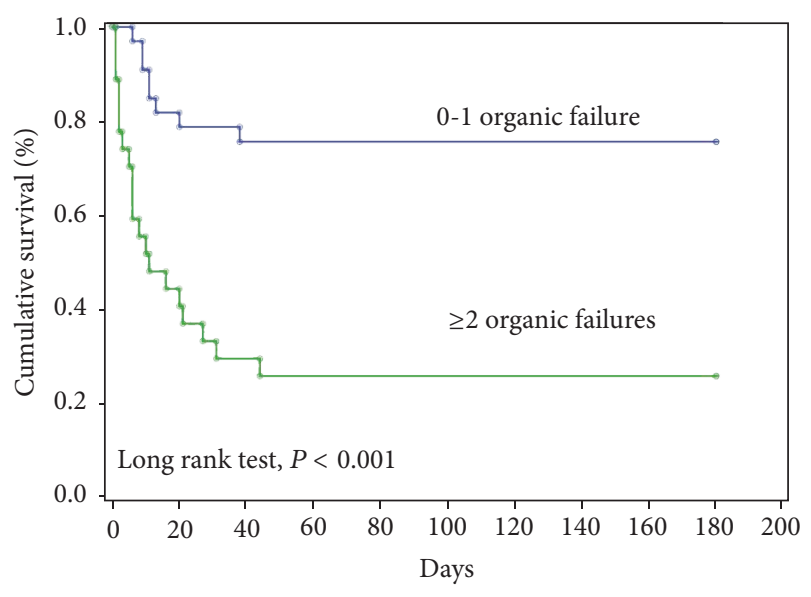

FIGURE 1: Six-month survival by number of organ failures.

After the orchiectomy 14 patients $(23.3 \%)$ received radiotherapy, and 52 patients (86.7\%) received chemotherapy. Sixty percent of the patients received first-line therapy. Those patients who experienced an incomplete response to first-line therapy were treated with second-line therapy $(16 / 30.7 \%)$. Forty-nine patients $(81.7 \%)$ were classified as having a poor prognosis, 9 patients (15\%) as having an intermediate prognosis, and 2 patients (3.3\%) as having a good prognosis. The main reasons for ICU admission were septic shock and postoperative care in 17 patients $(28.3 \%)$, respectively, followed by acute respiratory failure in 13 patients $(21.7 \%)$. The incidence of organ failure was noted most frequently for the respiratory (33/55\%), cardiovascular (26/43.3\%), and renal systems $(12 / 20 \%)$. During the first 24 hours of ICU admission, invasive MV was required by 43 patients $(71.6 \%)$ for a median duration of 3 (interquartile range, 1-7) days, and vasopressors were required for 27 patients (24\%). The median length of stay in the hospital wards before ICU admission was 2 days (1-7) (Table 1). The length of stay in the ICU and hospital was $3(2-6)$ and $8(5-15)$ days, respectively. Table 2 lists the main characteristics of the patients according to the presence of hospital mortality and Table 3 presents the laboratory parameters according to hospital mortality. The ICU, hospital, and 6-month mortality rates were $38.3 \%$, $45 \%$, and $63.3 \%$, respectively. The Cox multivariate analysis identified the white blood cells count $(\mathrm{HR}=1.06,95 \% \mathrm{CI}=$ 1.01-1.11, and $P=0.005$ ), ionized calcium (iCa) level ( $\mathrm{HR}=$ $1.23,95 \% \mathrm{CI}=1.01-1.50$, and $P=0.037$ ), and 2 or more organ failures during the first 24 hours after ICU admission (HR $=3.86$, 95\% CI $=1.96-7.59$, and $P<0.001)$ as independent predictors of death for up to 6 months (Table 4). The sixmonth survival by number of organ failures is presented in Figure 1.

\section{Discussion}

In this study of 60 critically ill patients with TC who were admitted to the ICU, the ICU, hospital, and 6-month mortality rates were $38.3 \%, 45 \%$, and $63.3 \%$, respectively. To the best of our knowledge, no other group has conducted any 
TABLE 1: Clinical characteristics of critically ill patients with testicular cancer admitted to the intensive care unit $(n=60)$.

\begin{tabular}{|c|c|}
\hline Characteristic & Finding \\
\hline Age, years, mean $\pm S D$ & $28.3 \pm 8.2$ \\
\hline \multicolumn{2}{|l|}{ Primary histology, $n(\%)$} \\
\hline Nonseminomatous germ cell tumors & $55(91.7)$ \\
\hline Seminoma & $5(8.3)$ \\
\hline Metastasis & $58(96.7)$ \\
\hline \multicolumn{2}{|l|}{ Sites of metastasis, $n(\%)$} \\
\hline Pulmonary & $6(10)$ \\
\hline Extrapulmonary & $17(28.3)$ \\
\hline Mixed & $35(58.3)$ \\
\hline \multicolumn{2}{|l|}{ Stages, $n(\%)$} \\
\hline IIB/IIC & $8(13.3)$ \\
\hline IIIA/IIIB/IIIC & $52(86.7)$ \\
\hline \multicolumn{2}{|l|}{ IGCCCG, $n(\%)$} \\
\hline Good & $2(3.3)$ \\
\hline Intermediate & $9(15.0)$ \\
\hline Poor & $49(81.7)$ \\
\hline \multicolumn{2}{|l|}{ Tumor marker, median (IQR) } \\
\hline$\alpha$-Fetoprotein, $\mu \mathrm{g} / \mathrm{L}$ & $4.17(2.11-173)$ \\
\hline Human chorionic gonadotropin, U/L & $2.02(0-12,189)$ \\
\hline Lactate dehydrogenase, $\mathrm{U} / \mathrm{L}$ & $421.5(194.5-1,304.5)$ \\
\hline \multicolumn{2}{|l|}{ Characteristics on admission to the ICU } \\
\hline Need for vasopressors, $n(\%)$ & $27(45)$ \\
\hline Need for IMV, $n(\%)$ & $43(41.7)$ \\
\hline Need for hemodialysis, $n(\%)$ & $1(1.7)$ \\
\hline Length of IMV (days), median (IQR) & $3(1-7)$ \\
\hline PEEP, median (IQR) & $6(5-9)$ \\
\hline In hospital wards time before ICU admission, $n(\%)$ & $49(81.6)$ \\
\hline Length of stay in hospital wards before ICU admission, (days), median (IQR) & $2(1-7)$ \\
\hline APACHE score, mean \pm SD & $14.7 \pm 6.4$ \\
\hline MEXSOFA, mean \pm SD & $6.7 \pm 4.0$ \\
\hline \multicolumn{2}{|l|}{ Performance status, $n$ (\%) } \\
\hline $0-2$ & $34(56.7)$ \\
\hline $3-4$ & $26(43.3)$ \\
\hline \multicolumn{2}{|l|}{ Outcome data } \\
\hline Length of stay in ICU, days, median (IQR) & $3(2-6)$ \\
\hline Length of hospital stay, days, median (IQR) & $8(5-15)$ \\
\hline ICU mortality, $n(\%)$ & $23(38.3)$ \\
\hline Hospital mortality, $n(\%)$ & $27(45.0)$ \\
\hline 6-month mortality, $n(\%)$ & $38(63.3)$ \\
\hline
\end{tabular}

SD, standard deviation. IMV, invasive mechanical ventilation. IQR, interquartile range. ICU, intensive care unit. SOFA, sequential organ failure assessment. APACHE, Acute Physiology and Chronic Health Evaluation. SAPS, Simplified Acute Physiology Score. IGCCCG, the International Germ Cell Cancer Collaborative Group. 
TABLE 2: Characteristics of the patients according to the presence of hospital mortality.

\begin{tabular}{|c|c|c|c|}
\hline Variable & $\begin{array}{l}\text { Survivor } \\
(n=32)\end{array}$ & $\begin{array}{l}\text { Nonsurvivor } \\
\quad(n=28)\end{array}$ & $P$ \\
\hline Age, years, mean $\pm S D$ & $27.2 \pm 8.4$ & $29.5 \pm 7.8$ & 0.271 \\
\hline APACHE II, point, mean $\pm S D$ & $13 \pm 6.39$ & $16.6 \pm 6$ & 0.033 \\
\hline$M E X S O F A$, mean $\pm S D$ & $4.7 \pm 3.3$ & $8.9 \pm 3.6$ & $<0.001$ \\
\hline \multicolumn{4}{|l|}{ Primary histology, $n$ (\%) } \\
\hline Nonseminomatous germ cell tumors & $30(93.7)$ & $25(89.2)$ & \multirow[t]{2}{*}{0.657} \\
\hline Seminomatous germ cell tumors & $2(6.2)$ & $3(10.7)$ & \\
\hline \multicolumn{4}{|l|}{ Metastasis, $n(\%)$} \\
\hline No & $0(0)$ & $2(7.1)$ & \multirow[t]{2}{*}{0.214} \\
\hline Yes & $32(100)$ & $26(92.8)$ & \\
\hline \multicolumn{4}{|l|}{ Sites of metastasis, $n(\%)$} \\
\hline Pulmonary & $2(6.2)$ & $4(15.3)$ & \multirow[t]{3}{*}{0.408} \\
\hline Extrapulmonary & $11(34.3)$ & $6(23)$ & \\
\hline Mixed & $19(59.3)$ & $16(61.5)$ & \\
\hline \multicolumn{4}{|l|}{ IGCCCG risk classification } \\
\hline Good & $0(0)$ & $2(7.1)$ & \multirow[t]{3}{*}{0.240} \\
\hline Intermediate & $4(12.5)$ & $5(17.8)$ & \\
\hline Poor & $28(87.5)$ & $21(75)$ & \\
\hline \multicolumn{4}{|l|}{ ECOG performance status, $n(\%)$} \\
\hline $0-2$ & $20(62.5)$ & $14(50)$ & \multirow[t]{2}{*}{0.330} \\
\hline $3-4$ & $12(37.5)$ & $14(50)$ & \\
\hline \multicolumn{4}{|l|}{ Tumor Marker, median (IQR) } \\
\hline$\alpha$-fetoprotein, $\mu \mathrm{g} / \mathrm{L}$ & $3.53(2.19-27)$ & $7.28(2.0-336.5)$ & 0.662 \\
\hline Human chorionic gonadotropin, U/L & $0(0-2.98)$ & $12,189(13-191,015)$ & $<0.001$ \\
\hline Lactate dehydrogenase, $\mathrm{U} / \mathrm{L}$ & $214(155.5-361.5)$ & $1,251(465.5-2,361.5)$ & $<0.001$ \\
\hline \multicolumn{4}{|l|}{ Need for vasopressors, $n(\%)$} \\
\hline Yes & $24(75)$ & $9(32.1)$ & \multirow[t]{2}{*}{0.001} \\
\hline No & $8(25)$ & $19(67.8)$ & \\
\hline \multicolumn{4}{|l|}{ Need for IMV, $n(\%)$} \\
\hline Yes & $19(59.3)$ & $24(85.7)$ & \multirow[t]{2}{*}{0.024} \\
\hline No & $13(40.7)$ & $4(14.3)$ & \\
\hline Length of IMV, day & $1(0-4)$ & $2.5(1-8.5)$ & 0.015 \\
\hline Length of stay in ICU, median, (IQR) & $2.5(2-5)$ & $3(1.5-8.5)$ & 0.001 \\
\hline Length of stay in hospital wards before ICU admission, median (IQR) & $1.5(1-5)$ & $1(0-6)$ & $<0.001$ \\
\hline
\end{tabular}

APACHE, Acute Physiology and Chronic Health Evaluation. ICU, intensive care unit. IGCCCG, International Germ Cell Cancer Collaborative Group. ECOG, Eastern Cooperative Oncology Group. IMV, invasive mechanical ventilation.

study in these patients. Patients who had two or more organ system failures during the first 24 hours after ICU admission had a high mortality rate. Germ cell tumors (GCTs) are uncommon tumors that constitute only $2 \%$ of all human malignancies, but they are the most common solid tumor in men between 15 and 34 years of age [1]. GCTs are highly sensitive to radiotherapy and chemotherapy; however, stage is an important predictor of survival and patients with poor prognosis have a five-year survival rate of approximately $50 \%$ [9]. In this study, more than $80 \%$ of patients were in advanced stages of the disease at ICU admission; this could be related to a low survival (37\%) to 6 months.

In our series, the independent predictors of death at 6 months were white blood cells count, ionized calcium level, and 2 or more organ failures during the first 24 hours after ICU admission. 
TABLE 3: Laboratory parameters according to hospital mortality.

\begin{tabular}{|c|c|c|c|c|}
\hline Variable & $\begin{array}{l}\text { All patients } \\
(n=60)\end{array}$ & $\begin{array}{l}\text { Survivor } \\
(n=32)\end{array}$ & $\begin{array}{l}\text { Nonsurvivor } \\
\quad(n=28)\end{array}$ & $P$ \\
\hline Hemoglobin, $g / d l$, mean $\pm S D$ & $10.1 \pm 2.3$ & $10.9 \pm 1.9$ & $9.1 \pm 2.3$ & 0.001 \\
\hline White blood cells count, $10^{3}$ cells $/ \mathrm{mm}^{3}$ & $12.4 \pm 7.4$ & $10.7 \pm 4.6$ & $14.4 \pm 9.5$ & 0.065 \\
\hline Neutrophils, $10^{3}$ cells $/ \mathrm{mm}^{3}$ & $10.5(6.15-14.5)$ & $9.45(5.3-11.7)$ & $11.25(7.8-16.9)$ & 0.087 \\
\hline Lymphocytes, $10^{3}$ cells $/ \mathrm{mm}^{3}$ & $0.7(0.4-1.2)$ & $0.75(0.5-1.0)$ & $0.55(0.3-1.6)$ & 0.672 \\
\hline Platelets, $10^{3}$ cells $/ \mathrm{mm}^{3}$ & 187.5 & $196.2 \pm 121.2$ & $177.7 \pm 117.7$ & 0.552 \\
\hline Serum creatinine, $\mathrm{mg} / \mathrm{dL}$ & $0.9(0.7-1.6)$ & $0.88(0.7-1.3)$ & $1.1(0.7-1.8)$ & 0.310 \\
\hline Glucose, $\mathrm{mg} / \mathrm{dL}$ & $137 \pm 44.3$ & $135.5 \pm 43.4$ & $140.4 \pm 46$ & 0.672 \\
\hline Uric acid, mg/dL & $5.7 \pm 3$ & $5.3 \pm 2.5$ & $6.2 \pm 3.5$ & 0.276 \\
\hline \multicolumn{5}{|l|}{ Serum electrolytes } \\
\hline Sodium, $\mathrm{mEq} / \mathrm{L}$ & $136.7 \pm 4.2$ & $136.5 \pm 4.1$ & $137.1 \pm 4.4$ & 0.588 \\
\hline Potassium, $\mathrm{mEq} / \mathrm{dL}$ & $4.4 \pm 0.9$ & $4.1 \pm 0.6$ & $4.7 \pm 1.2$ & 0.029 \\
\hline Chlorine, $\mathrm{mEq} / \mathrm{dL}$ & $106.9 \pm 6.3$ & $106.9 \pm 7$ & $106.9 \pm 5.7$ & 0.998 \\
\hline Magnesium, mg/dL & $2 \pm 0.4$ & $1.9 \pm 0.4$ & $2.2 \pm 0.4$ & 0.025 \\
\hline Phosphorus, mg/dL & $4.2(3.6-5.2)$ & $4.1(3.1-4.6)$ & $4.4(3.7-6.2)$ & 0.073 \\
\hline Ionized calcium, $\mathrm{mmol} / \mathrm{L}$ & $0.8(0.7-1)$ & $0.8(0.7-1)$ & $0.8(0.8-1)$ & 0.794 \\
\hline Total bilirubin, mg/dL & $1.1(0.7-2.1)$ & $0.8(0.6-1.8)$ & $1.5(0.9-2.9)$ & 0.013 \\
\hline Albumin, g/dL & $2.1(1.6-2.8)$ & $2.5(1.9-3.1)$ & $1.8(1.5-2.4)$ & 0.002 \\
\hline \multicolumn{5}{|l|}{ Lactate, $\mathrm{mmol} / \mathrm{L}$} \\
\hline ICU admission & $2(1.4-3.5)$ & $2.3(1.4-3.4)$ & $1.7(1.5-3.6)$ & 0.772 \\
\hline Stay in ICU & $1.5(1.1-2)$ & $1.4(0.9-1.9)$ & $1.9(1.3-2)$ & 0.038 \\
\hline
\end{tabular}

ICU, intensive care unit.

An elevated white blood cell count typically reflects the normal response of bone marrow to an infectious or inflammatory process $[10,11]$. A high white blood cell count is associated with an increased risk of cancer-related mortality. Local inflammatory processes that have long been known to be associated with tumor progression may be reflected in the systemic inflammatory marker of a higher white blood cell count [12]. Approximately one-third of the patients included in our study were admitted to the ICU with septic shock, and more than $80 \%$ were in advanced stages of the disease; both scenarios are possibly related to the fact that leukocytosis is a factor independent of death in critically ill patients with TC. Although the serum tumor markers alphafetoprotein, lactate dehydrogenase, and $\beta$-human chorionic gonadotropin $(\beta-\mathrm{HCG})$ are critical in diagnosing GCTs, determining the prognosis, and assessing the treatment outcome [1], these biomarkers were not predictors of a poor prognosis in patients with testicular cancer during their stay in the ICU. The serum levels of these biomarkers should not be considered when deciding whether a patient is eligible to be admitted to the ICU. The white blood cell count is advantageous due to its simplicity, low cost, and availability and may be used to identify patients at high risk of poor outcomes.

In hospitalized cancer patients the reported incidence of hypocalcaemia is less than $11 \%$ [13]. The measurement of serum $\mathrm{iCa}$ is common in patients admitted to ICUs, at least half of which will have values outside the reference range during the ICU stay. The majority of these patients do not have an underlying disease of calcium homeostasis [14]. Derangements in iCa levels occur very commonly in critically ill patients, especially those with sepsis, and are usually not the result of an underlying disease of calcium homeostasis [14]. In nonseptic, critically ill adults, hypocalcaemia has also been reported [15]. Hypocalcaemia as a prognostic factor in critically ill cancer patients has never been studied. In our series, the iCa levels were low in both survivors and nonsurvivors during their hospital stay; however, ionized calcium level was an independent factor of death at six months. Measures of iCa during the ICU and hospital stay may prevent asymptomatic stages of hypocalcaemia or lead to their early detection and correction, as well as improve the outcomes of critically ill patients with TC.

The main prognostic factors in critically ill cancer patients admitted to the ICU are degree of dysfunction, number of organ failures, and performance status at ICU admission [1618]. The results suggest that the number of organ failures during the ICU stay of patients with TC appears crucial to predicting the outcome. Consequently, organ failure may be a simple and objective tool for oncologists and intensivists to identify patients who should be admitted earlier to the ICU. 
TABLE 4: Univariable and multivariable analysis of factors associated with 6-month mortality $(n=60)$.

\begin{tabular}{|c|c|c|c|c|c|c|}
\hline \multirow{2}{*}{ Variable } & Hazard ratio & $95 \% \mathrm{CI}$ & $P$ & Hazard ratio & $95 \% \mathrm{CI}$ & $P$ \\
\hline & \multicolumn{3}{|c|}{ Univariate } & \multicolumn{3}{|c|}{ Multivariate } \\
\hline APACHE II & 1.04 & $0.99-1.09$ & 0.570 & & & \\
\hline MEXSOFA & 1.12 & $1.04-1.21$ & 0.001 & & & \\
\hline Hemoglobin, gr/dL & 0.79 & $0.68-0.93$ & 0.005 & & & \\
\hline White blood cells & 1.05 & $1.005-1.10$ & 0.032 & 1.06 & $1.01-1.11$ & 0.005 \\
\hline Lymphocytes, $10^{3}$ cells $/ \mathrm{mm}^{3}$ & 0.99 & $0.86-1.13$ & 0.911 & & & \\
\hline Platelets, $10^{3}$ cells $/ \mathrm{mm}^{3}$ & 1.00 & $0.99-1.00$ & 0.845 & & & \\
\hline Neutrophils, $10^{3}$ cells $/ \mathrm{mm}^{3}$ & 1.05 & $0.99-1.10$ & 0.590 & & & \\
\hline Serum creatinine, mg/dL & 1.00 & $0.92-1.09$ & 0.915 & & & \\
\hline Glucose, mg/dL & 0.99 & $0.99-1.00$ & 0.863 & & & \\
\hline Uric acid, $\mathrm{mg} / \mathrm{dL}$ & 1.06 & $0.95-1.18$ & 0.245 & & & \\
\hline \multicolumn{7}{|l|}{ Serum electrolytes } \\
\hline Sodium, mEq/L & 1.01 & $0.94-1.10$ & 0.661 & & & \\
\hline Potassium, mEq/L & 1.54 & $1.10-2.14$ & 0.011 & & & \\
\hline Chlorine, $\mathrm{mEq} / \mathrm{L}$ & 0.98 & $0.93-1.03$ & 0.500 & & & \\
\hline Magnesium, mg/dL & 2.25 & $1.11-4.57$ & 0.024 & & & \\
\hline Phosphorus, mg/dL & 1.25 & $1.09-1.45$ & 0.002 & & & \\
\hline Ionized calcium, $\mathrm{mmol} / \mathrm{L}$ & 1.17 & $0.96-1.43$ & 0.103 & 1.23 & $1.01-1.50$ & 0.037 \\
\hline Total bilirubin, mg/dL & 1.06 & $0.94-1.19$ & 0.284 & & & \\
\hline Albumin, g/dL & 0.88 & $0.69-1.14$ & 0.356 & & & \\
\hline \multicolumn{7}{|l|}{ Lactate, $\mathrm{mmol} / \mathrm{L}$} \\
\hline ICU admission & 0.92 & $0.77-1.10$ & 0.361 & & & \\
\hline Stay in ICU & 1.28 & $0.91-1.80$ & 0.146 & & & \\
\hline ECOG, (3-4) & 1.53 & $0.80-2.90$ & 0.190 & & & \\
\hline$\geq 2$ organic failures & 3.09 & $1.61-5.95$ & 0.001 & 3.86 & $1.96-7.59$ & $<0.001$ \\
\hline
\end{tabular}

ICU, intensive care unit. APACHE, Acute Physiology and Chronic Health Evaluation. ECOG, Eastern Cooperative Oncology Group.

Our study has some limitations in that it was undertaken at a single center, which may restrict the generalizability, and the sample size was small.

\section{Conclusion}

The ICU, hospital, and 6-month mortality rates were $38.3 \%$, $45 \%$, and $63.3 \%$, respectively. The factors associated with an increased 6-month mortality rate were white blood cells count, iCa level, and 2 or more organ failures during the first 24 hours after ICU admission.

\section{Disclosure}

This study was presented in part at Chest 2016, Annual Meeting of the American College of Chest Physicians, October 22-26, 2016, in Los Angeles, California (DOI: https://doi.org/ 10.1016/j.chest.2016.08.348).

\section{Conflicts of Interest}

The authors declared no potential conflicts of interest with respect to the research, authorship, and/or publication of this article.

\section{References}

[1] R. J. Motzer, N. Agarwal, C. Beard et al., "Testicular cancer," Journal of the National Comprehensive Cancer Network, vol. 10, no. 4, pp. 502-535, 2012.

[2] K.-P. Dieckmann, J. T. Hartmann, J. Classen, M. Diederichs, and U. Pichlmeier, "Is increased body mass index associated with the incidence of testicular germ cell cancer?" Journal of Cancer Research and Clinical Oncology, vol. 135, no. 5, pp. 731-738, 2009.

[3] C. Kirch, F. Blot, K. Fizazi, B. Raynard, C. Theodore, and G. Nitenberg, "Acute respiratory distress syndrome after chemotherapy for lung metastases from non-seminomatous germ-cell tumors," Supportive Care in Cancer, vol. 11, no. 9, pp. 575-580, 2003.

[4] G. M. Mead, "International germ cell consensus classification: a prognostic factor- based staging system for metastatic germ cell cancers," Journal of Clinical Oncology, vol. 15, no. 2, pp. 594-603, 1997.

[5] M. M. Oken, R. H. Creech, and D. C. Tormey, "Toxicity and response criteria of the Eastern Cooperative Oncology Group," American Journal of Clinical Oncology, vol. 5, no. 6, pp. 649-655, 1982.

[6] W. A. Knaus, E. A. Draper, D. P. Wagner, and J. E. Zimmerman, "APACHE II: a severity of disease classification system," Critical Care Medicine, vol. 13, no. 10, pp. 818-829, 1985. 
[7] S. A. Namendys-Silva, M. A. Silva-Medina, G. M. VásquezBarahona et al., "Application of a modified sequential organ failure assessment score to critically ill patients," Brazilian Journal of Medical and Biological Research, vol. 46, no. 2, pp. 186-193, 2013.

[8] S. A. Ñamendys-Silva, M. O. González-Herrera, J. TexcocanoBecerra, and A. Herrera-Gómez, "Clinical characteristics and outcomes of critically ill cancer patients with septic shock," QJM: An International Journal of Medicine, vol. 104, no. 6, pp. 505-511, 2011.

[9] E. Rajpert-De Meyts, K. A. McGlynn, K. Okamoto, M. A. S. Jewett, and C. Bokemeyer, "Testicular germ cell tumours," The Lancet, vol. 387, no. 10029, pp. 1762-1774, 2016.

[10] N. Abramson and B. Melton, "Leukocytosis: basics of clinical assessment," American Family Physician, vol. 62, no. 9, pp. 20532060, 2000.

[11] A. D. Shah, S. Thornley, S.-C. Chung, S. Denaxas, R. Jackson, and $\mathrm{H}$. Hemingway, "White cell count in the normal range and short-term and long-term mortality: International comparisons of electronic health record cohorts in England and New Zealand," BMJ Open, vol. 7, no. 2, Article ID e013100, 2017.

[12] A. Shankar, J. J. Wang, E. Rochtchina, M. C. Yu, R. Kefford, and P. Mitchell, "Association between circulating white blood cell count and cancer mortality. A population-based cohort study," JAMA Internal Medicine, vol. 166, no. 2, pp. 188-194, 2006.

[13] E. D’Erasmo, M. Acca, F. Saverio Celi et al., "A hospital survey of hypocalcemia and hypophosphatemia in malignancy," TUMORI, vol. 77, no. 4, pp. 311-314, 1991.

[14] S. K. Aberegg, "Ionized calcium in the ICU should it be measured and corrected?" CHEST, vol. 149, no. 3, pp. 846-855, 2016.

[15] J. R. Zivin, T. Gooley, R. A. Zager, and M. J. Ryan, "Hypocalcemia: A pervasive metabolic abnormality in the critically ill," American Journal of Kidney Diseases, vol. 37, no. 4, pp. 689-698, 2001.

[16] M. Soares, P. Caruso, E. Silva et al., "Characteristics and outcomes of patients with cancer requiring admission to intensive care units: a prospective multicenter study," Crit Care Med, vol. 38, pp. 9-15, 2010.

[17] B. Lamia, M.-F. Hellot, C. Girault et al., "Changes in severity and organ failure scores as prognostic factors in onco-hematological malignancy patients admitted to the ICU," Intensive Care Medicine, vol. 32, no. 10, pp. 1560-1568, 2006.

[18] F. S. Taccone, A. A. Artigas, C. L. Sprung, R. Moreno, Y. Sakr, and J.-L. Vincent, "Characteristics and outcomes of cancer patients in European ICUs," Critical Care, vol. 13, no. 1, article no. R15, 2009. 


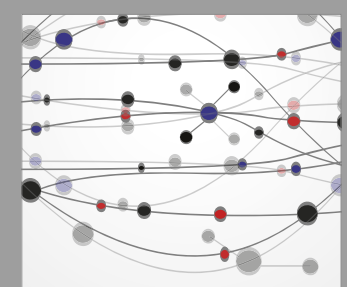

The Scientific World Journal
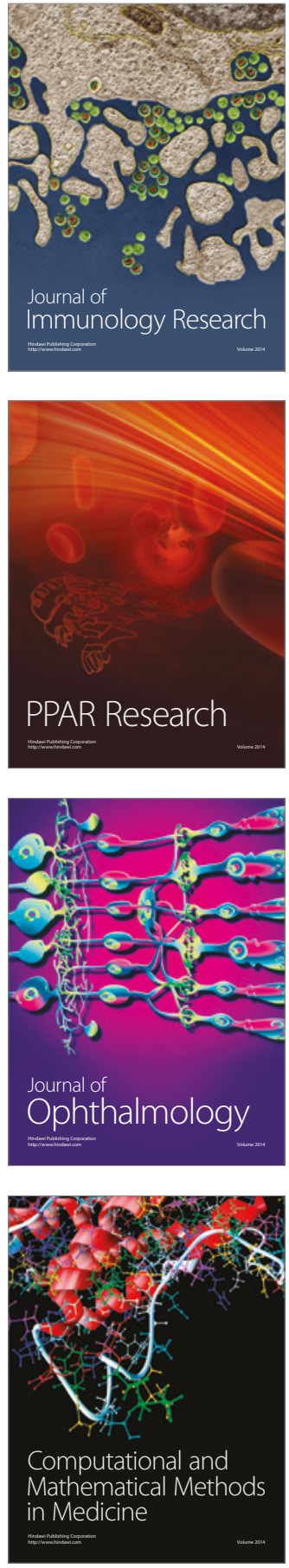

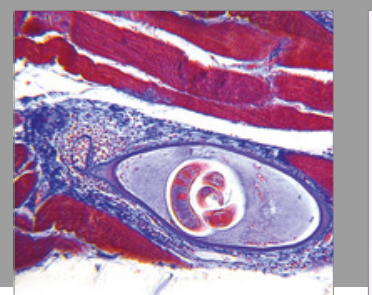

Gastroenterology Research and Practice
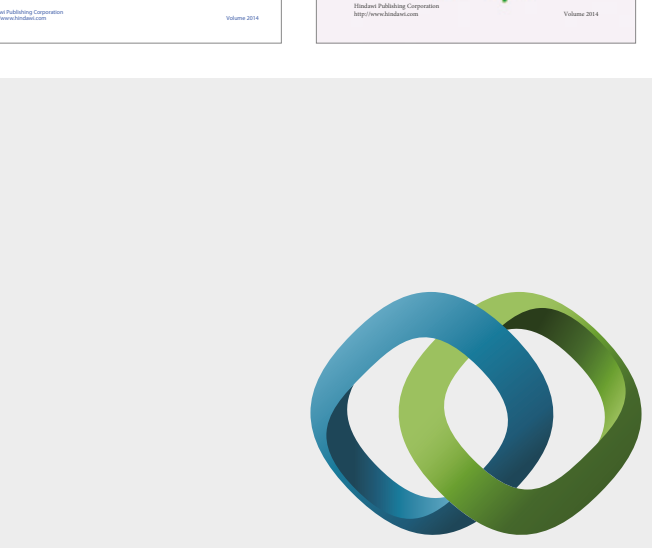

\section{Hindawi}

Submit your manuscripts at

https://www.hindawi.com
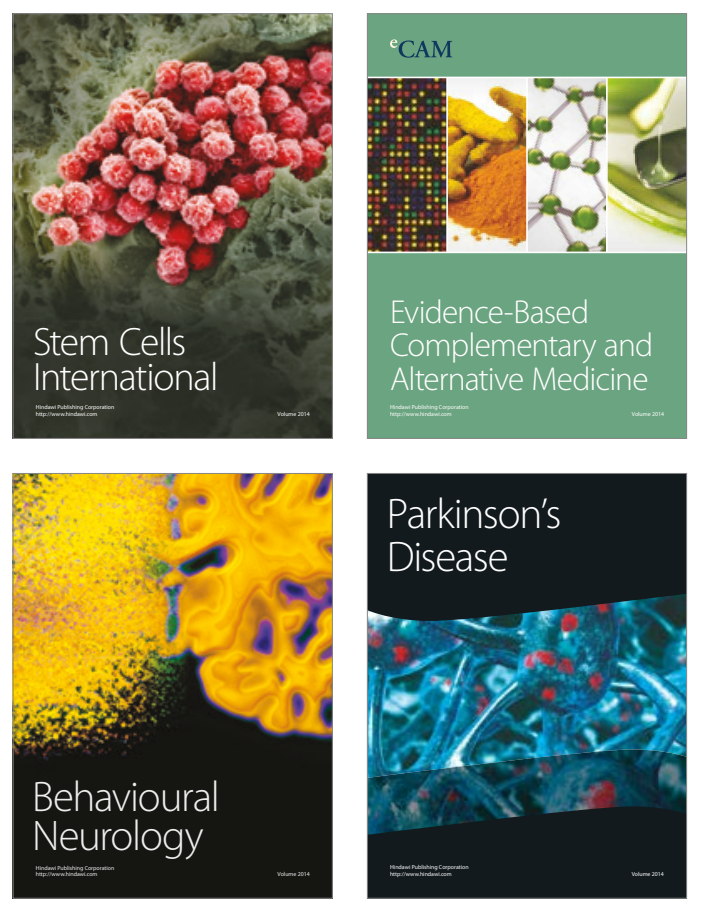
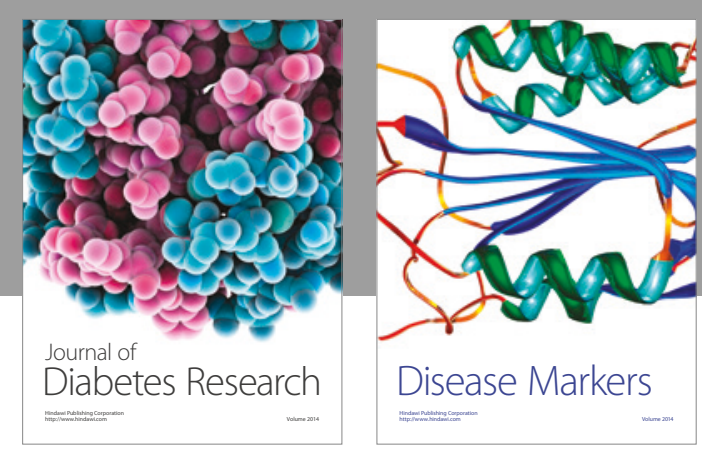

Disease Markers
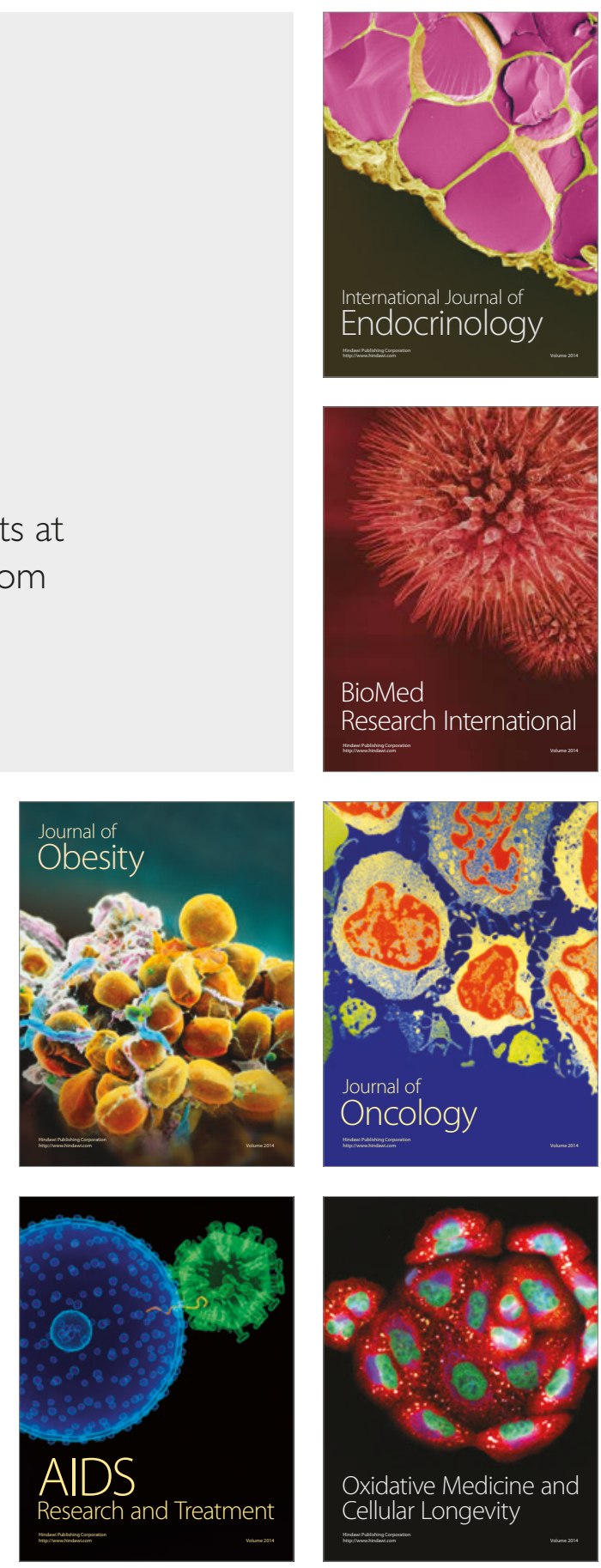